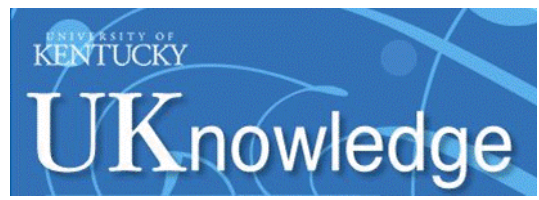

University of Kentucky

UKnowledge

\title{
On the Effect of Design Tolerances on the Performance of Synchronous PM Machines Evaluated According to the IEEE Std
} 1812

\author{
Narges Taran \\ University of Kentucky, narges.taran@uky.edu \\ Vandana Rallabandi \\ University of Kentucky, vandana.rallabandi@uky.edu \\ Dan M. Ionel \\ University of Kentucky, dan.ionel@uky.edu \\ Ping Zhou \\ ANSYS, Inc.
}

Follow this and additional works at: https://uknowledge.uky.edu/peik_facpub

Part of the Power and Energy Commons

Right click to open a feedback form in a new tab to let us know how this document benefits you.

\section{Repository Citation}

Taran, Narges; Rallabandi, Vandana; Ionel, Dan M.; and Zhou, Ping, "On the Effect of Design Tolerances on the Performance of Synchronous PM Machines Evaluated According to the IEEE Std 1812" (2017). Power and Energy Institute of Kentucky Faculty Publications. 45.

https://uknowledge.uky.edu/peik_facpub/45

This Conference Proceeding is brought to you for free and open access by the Power and Energy Institute of Kentucky at UKnowledge. It has been accepted for inclusion in Power and Energy Institute of Kentucky Faculty Publications by an authorized administrator of UKnowledge. For more information, please contact UKnowledge@lsv.uky.edu. 


\title{
On the Effect of Design Tolerances on the Performance of Synchronous PM Machines Evaluated According to the IEEE Std 1812
}

\author{
Digital Object Identifier (DOI) \\ https://doi.org/10.1109/IEMDC.2017.8002387
}

\section{Notes/Citation Information}

Published in 2017 IEEE International Electric Machines and Drives Conference (IEMDC).

(C) 2017 IEEE Copyright Notice. "Personal use of this material is permitted. Permission from IEEE must be obtained for all other uses, in any current or future media, including reprinting/republishing this material for advertising or promotional purposes, creating new collective works, for resale or redistribution to servers or lists, or reuse of any copyrighted component of this work in other works."

The document available for download is the authors' manuscript version that is accepted for publication. The final published version is copyrighted by IEEE and available as: N. Taran, V. Rallabandi, D. M. Ionel and P. Zhou, "On the effect of design tolerances on the performance of synchronous PM machines evaluated according to the IEEE Std 1812," 2017 IEEE International Electric Machines and Drives Conference (IEMDC), Miami,FL, 2017, pp. 1-7. doi: 10.1109/IEMDC.2017.8002387 


\title{
On the Effect of Design Tolerances on the Performance of Synchronous PM Machines Evaluated According to the IEEE Std 1812
}

\author{
Narges Taran ${ }^{1}$, Vandana Rallabandi ${ }^{1}$, Dan M. Ionel ${ }^{1}$, Fellow, IEEE, and Ping Zhou ${ }^{2}$, Fellow, IEEE \\ ${ }^{1}$ Department of Electrical and Computer Engineering, University of Kentucky, Lexington, KY, USA \\ narges.taran@uky.edu, vandana.rallabandi@uky.edu,dan.ionel@uky.edu \\ ${ }^{2}$ ANSYS, Inc., Pittsburgh, PA, USA, ping.zhou@ ansys.com
}

\begin{abstract}
In the process of designing an electric machine, the systematic study of tolerances for the design variables and material properties is of the utmost importance. This paper proposes a method by which possible variations of the design variables and material properties can be distinguished. The design of experiments (DOE) technique, open-circuit and shortcircuit tests, with minimum instrumentation requirements, have been employed. Virtual tests are conducted based on the recently approved IEEE 1812 testing guide for PM synchronous machines. As a case study, a 100 hp 16-pole 18-slot spoke-type PM machine is discussed. It is shown that variation in magnet remanence, steel grade, as well as dimensional tolerances, may be identified. The ratings and magnetic loading of the machine plays a critical role in identifying manufacturing tolerances.
\end{abstract}

Keywords-Permanent Magnet Spoke-Type Machines, Design Variable Tolerances, Design of Experiments, Sensitivity Analysis, IEEE std 1812.

\section{INTRODUCTION}

The optimization of electric machine design has been progressing for years such that nowadays, engineers have, to a great extent, the knowledge and means for optimal design. However the performance of prototyped or mass produced machines frequently differs from predictions. These deviations from the designed performance may be due to manufacturing tolerances.

The systematic study of tolerances for the design variables and material properties is essential for successful research, development, and production of electric machines. This topic is of great interest to industry and yet only few papers have been published on the subject matter. Some instances for permanent magnet (PM) machines include the use of stochastic response surface method (RSM) in order to establish the effect of manufacturing tolerances on the torque output [1]. Computational estimation of the cogging torque accounting for the manufacturing tolerances in interior PM (IPM) machines is reported in [2]. The effect of geometrical asymmetries, caused by manufacturing variations, on cogging torque in surface

The support of University of Kentucky, the L. Stanley Pigman endowment, and ANSYS, Inc. is gratefully acknowledged. mounted PM (SPM) machines is explored in [3]. Other studies, such as [4]-[6] also discuss the impact of deviations on torque fluctuations and cogging torque. The influence of tolerances on other parameters, such as electromotive force (EMF), [7], air-gap flux density [8], is also investigated. The repercussions of manufacturing variations are examined through a screening and response surface method to identify the most important input design variables affecting the performance [9].

The present paper brings further contributions to the subject by specifically considering the performance evaluated through tests as specified in the recently approved IEEE 1812 testing guide for synchronous PM machines. In particular, the standardized open-circuit and short-circuit tests are considered. These two tests are the most straightforward, as they only require an external driving machine and standard electric measurement instrumentation, without the need for a torque transducer, position sensor, power electronic drive for the test machine, or other additional equipment. In order to reduce the effort associated with physical prototyping and to eliminate possible uncontrolled imperfections, virtual prototyping and testing based on electromagnetic finite element (FE) models, which has been successfully validated over the years, is employed in the paper. The main objective of the proposed procedure is to establish if out of specification tolerances on main dimensional variables and on the magnetic material properties can be traced early on in the development process, just through the combination of aforementioned simplest IEEE Standard 1812 tests.

Two PM machines are considered, including a $100 \mathrm{hp} \mathrm{16-}$ pole 18-slot spoke-type PM motor with rare earth magnets recently reported as a record braking ultra-high specific torque design for Formula E racing cars [10]; and another machine design, obtained by replacing the rare earth magnets in the Formula E motor with ceramic ferrites to bring down the ultrahigh electromagnetic loading to a more typical level. More details on the spoke-type motor specification, the variables and their possible tolerance ranges are discussed in the next section. Section III is dedicated to the analytical prediction of the sensitivity of output parameters to the tolerances. Opencircuit and short-circuit guidelines based on the IEEE 1812 


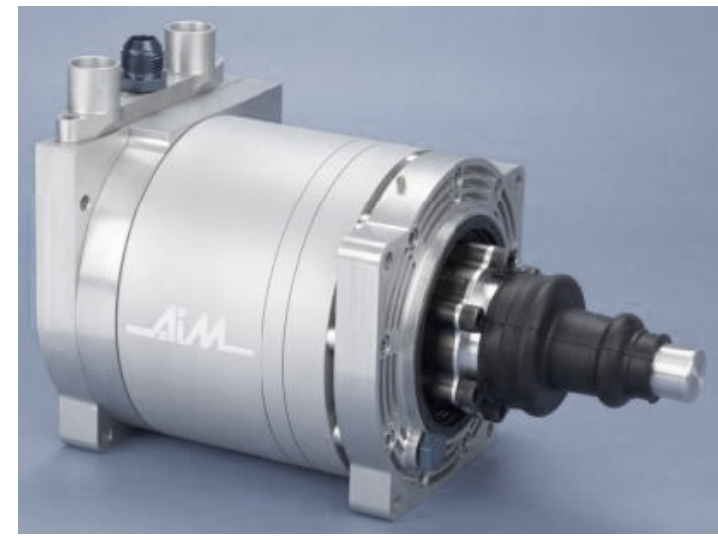

Figure 1. IPM spoke-type motor (100 hp) with rare earth magnets and ultrahigh torque density $(12.2 \mathrm{Nm} / \mathrm{kg})$ for Formula E racing cars [10]. Photo courtesy of Equipmake, Ltd.

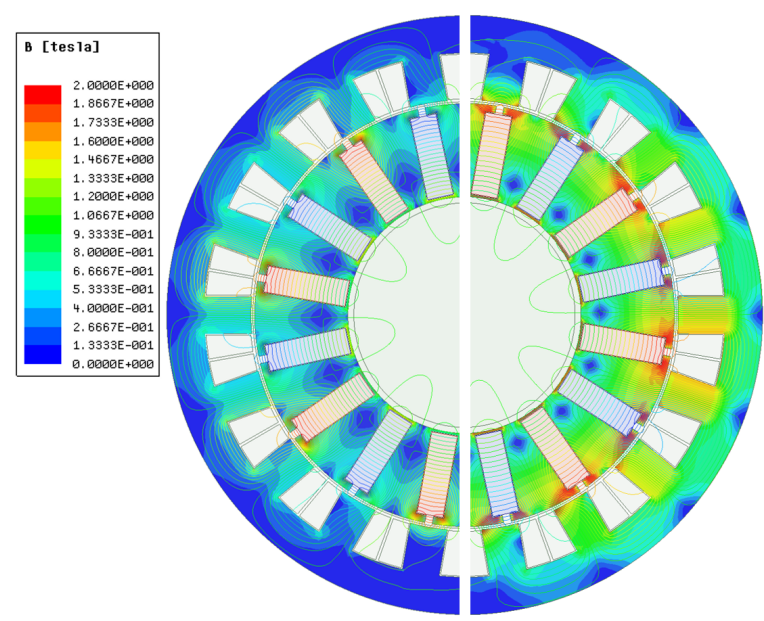

Figure 2. Flux density distribution and flux lines for the motor with ferrite magnets (left) and the same topology with thermally robust SmCo magnets (right).

Std are described in section IV. The results of design of experiments (DOE) and sensitivity analysis are presented and discussed in the next section. The last part draws conclusions following from the results and discussions in the previous sections.

\section{SPOKe-Type Motor Dimensional And Magnetic PROPERTIES TOLERANCES}

The IPM machine considered for this study is inspired from, and not identical to, the machine optimally designed with record breaking high torque density for application in Formula E racing cars [10]. It is a $100 \mathrm{hp}$ motor with flux concentrating spoke-type rotor containing 16 rare earth PM poles and 18 slots that has been successfully prototyped (Fig. 1).

Thermal performance is the ultimate limiting factor in the power density of the motor. Operational temperature of this motor, with peak torque per total mass of $12.2 \mathrm{Nm} / \mathrm{kg}$, is very high (PM's temperature at $120^{\circ} \mathrm{C}$ ), hence the use of thermally robust samarium-cobalt $(\mathrm{SmCo})$ magnets (with

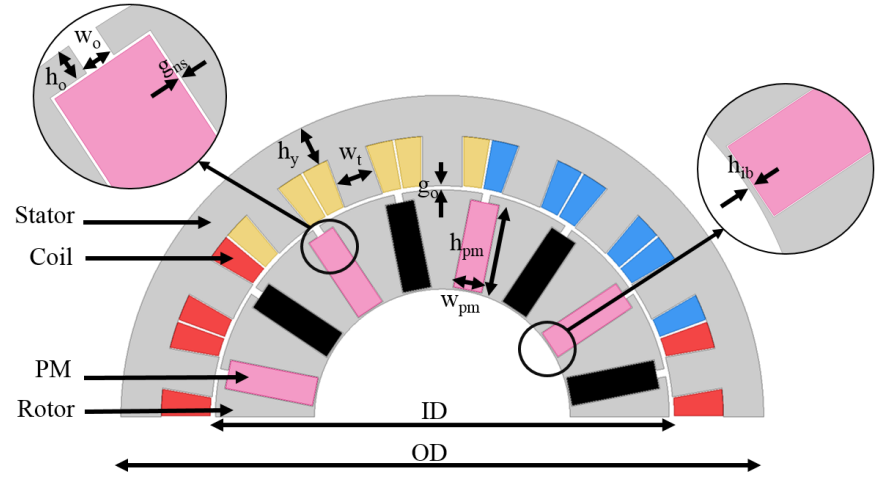

Figure 3. Overview of the investigated geometrical design variables of the 2D model analyzed with the ANSYS Maxwell software.

temperature coefficient of less than $0.05 \% /{ }^{\circ} \mathrm{C}$ ) is essential. For general applications of spoke-type rotors, the inherent flux concentration properties eliminate the need for rare earth magnets with high residual magnetic flux density, allowing these machines to be designed with weaker, less expensive ceramic ferrite magnets. Therefore, in this paper the same topology is also studied with ceramic ferrites to investigate the spoke-type motor's performance in a more typical level of electromagnetic loading.

In order to study and verify the fundamental performance of the design, 2D FE analysis is used. The flux density distributions for the machine with ferrite and rare earth magnets under reference specification (Fig. 2) show a very high magnetic flux density of the rotor core for the latter which, considering the flux concentration feature of a spoke-type machine, is in line with expectations.

Manufacturing tolerances are usually inevitable in mass production and prototyping of electric machines. The geometrical input design variables considered in this study are represented in Fig. 3. The specified values for each variable and their possible deviations are given in Table I and II. A tolerance of $\pm 0.1 \mathrm{~mm}$, typical for laser cutting prototyping, has been considered for geometrical variables.

There are several possible out of specification tolerances for magnet quality including eccentricity, inconsistency in magnetization direction, non-uniform magnet grade for different poles, geometrical nonuniformity, and incorrect positioning in assembly. In this paper, tolerance of $\pm 5 \%$ of the specified value is considered for the PM remanence in order to account for possible variation both in the material grade and in the external magnetization for prototypes. The specified material for the laminated core is M19 laminated silicon steel. As an example of deviation from the original specifications of the motor, it is considered that M43 may be inadvertently used within the same gauge.

The manufacturing tolerances are not limited to the factors mentioned in Table I and II; the air-gap may become uneven both as a result of eccentric assembly or laser cutting errors, the lamination material properties may be assigned incorrectly only for one of the rotor or stator cores, etc. The tolerances 
Table I

GeOMETRICAL VARIABles (FIG. 3). A TOLERANCE OF $\pm 0.1 \mathrm{MM}$ FOR GEOMETRICAL VARIABLES HAS BEEN CONSIDERED.

\begin{tabular}{llr}
\hline Geometrical factors & Reference spec. $[\mathrm{mm}]$ \\
\hline$x_{1}=O D$ & Outer diameter & 160 \\
$x_{2}=h_{y}$ & Yoke length & 10 \\
$x_{3}=w_{t}$ & Tooth width & 10 \\
$x_{4}=h_{i b}$ & Bridge height & 0.5 \\
$x_{5}=g_{o}$ & Air-gap & 1 \\
$x_{6}=h_{o}$ & Slot opening depth & 3 \\
$x_{7}=w_{p m}$ & PM width & 7 \\
$x_{8}=h_{p m}$ & PM height & 22 \\
$x_{9}=w_{o}$ & Slot opening width & 2 \\
$x_{10}=I D$ & Inner diameter & 115 \\
$x_{11}=g_{n s}$ & Nuisance gap & 0.2 \\
\hline
\end{tabular}

Table II

MAGNETIC GRADE REFERENCE VALUE AND TOLERANCES AND LAMINATION MATERIAL TOLERANCES IN INADVERTENTLY SUBSTITUTION. TWO PM MATERIALS HAS BEEN STUDIED: FERRITE AND SMCO WITH NOMINAL REMANENCE OF 0.4 T AND $1.1 \mathrm{~T}$, RESPECTIVELY.

\begin{tabular}{llcl}
\hline Magnetic & material factors & Reference & Tol./sub. \\
\hline$x_{12}: B_{r}$ & PM remanence & Nom. & $\pm 5 \%$ \\
$x_{13}: M$ & Lamination & M19 & M43 \\
\hline
\end{tabular}

on such factors are not within the scope of this study.

\section{Analytical Prediction of the Effect of TOLERANCES ON DESIGN VARIABLES}

According to the conventional theory, the open-circuit voltage, $V_{o c}$, of a PM synchronous machine can be analytically estimated as:

$$
\begin{aligned}
V_{o c}=2 \pi f_{1} \lambda_{m o}, \lambda_{m o} & =\frac{2}{\pi} k_{w 1} N_{t} k_{v g} \alpha_{i} B_{g o} \tau_{p} L_{F e}, \\
B_{g o} & =\frac{B_{r}}{\frac{\alpha_{i}}{k_{\sigma}} \frac{\tau_{p}}{k_{b} h_{p m}}+\frac{2 \mu_{m r} k_{c} k_{s o} g}{k_{h} w_{p m}}},
\end{aligned}
$$

where $f_{1}$ is the fundamental frequency; $\lambda_{m o}$, the open-circuit magnetizing flux linkage; $k_{w 1}$, the fundamental winding factor; $N_{t}$, number of turns per phase; $k_{v g}$, the ratio between the amplitude of the fundamental wave and the average value of the air-gap flux density; $B_{g o}$, the peak value of the opencircuit flux density; $\tau_{p}$ pole pitch; and $L_{F e}$, the core length; $h_{p m}$ and $w_{p m}$, the PM height and width (length in the direction of magnetization), respectively; $\alpha_{i}$, the pole-arc to pole-pitch ratio; $g$, the air-gap length; $k_{c}$, Carter's coefficient; $\mu_{m r}$, the relative permeability of the PM; $k_{s o}$, the $\mathrm{d}$ axis saturation factor at open-circuit operation; and $k_{\sigma}$, is the leakage coefficient estimated at $0.9-1$ - the lower values corresponding to the IPM and the upper ones to the SPM . The coefficient $k_{b}$ is equal to the number of PMs which provide the polar flux: 2 for IPM and 1 for SPM. The coefficient $k_{h}$ is equal to the number of times for which the medium length flux line is passing through the PMs: 1 for IPM and 2 for SPM. It should be noted that, as per (1), open-circuit voltage, $V_{o c}$, is directly proportional to air-gap flux density and inversely proportional to the airgap. Among the variables under study, represented in Table I and II, remanence and PM dimensions can influence $B_{g o}$. Since dimensional variations have secondary effects on $V_{o c}$, it is expected that the impacts of $B_{r}$ and $g$ are more considerable compared to those of other factors.

Core losses, $W_{F e}$, are proportional to

$$
W_{F e} \propto k_{h} f_{1} B^{\alpha}+k_{e} f_{1}^{2} B^{2},
$$

where $k_{h}$ and $k_{e}$ are the hysteresis and eddy current coefficients for the laminated steel. The coefficient $\alpha$ has values between $1.5-2.5$, and $B$ is the peak value of flux density in the core, which depends on the flux density in the air-gap (1). Hysteresis and eddy current coefficients are highly dependent on lamination material properties, hence any deviation from specified lamination material will result in inconsistency in expected and actual core losses. Moreover, any parameter that affects magnetic flux density in the core, including remanence and air-gap, can potentially result in deviations in core losses.

The d-axis inductance, $L_{d}$, may be estimated by

$$
\begin{aligned}
L_{d} & =\frac{2 m \mu_{0}\left(k_{w 1} N_{t}\right)^{2} \tau_{p} L_{F e}}{\pi^{2} p k_{c} g} \cdot \frac{k_{a d}}{k_{s d}}, \\
k_{a d} & =\frac{k_{c} g}{k_{c} g+\frac{k_{h}}{2} \frac{w_{p m}}{\mu_{m r}}},
\end{aligned}
$$

where $m$ is the number of phases; $p$, the number of pole pairs; and $k_{s d}$, d-axis saturation coefficient. Based on (3), it is expected that $L_{d}$ inductance depends on dimensional variables such as $g$ and $w_{p m}$, and only indirectly depends on the laminated steel and PM characteristics through the saturation factors. In the definition of $k_{a d}, g$ is weighted by Carter's coefficient while the effect of $w_{p m}$ has been mitigated. Hence, a larger sensitivity of $L_{d}$ to $g$ than to $w_{p m}$ is expected.

Equations (1), (2), and (3) may be used to conduct systematic analytical DOE and sensitivity analysis. Detailed DOE and sensitivity analysis from analytical calculations in comparison to numerical results are provided in section $\mathrm{V}$.

\section{Open-Circuit And Short-Circuit Virtual TESTING OF PM MOTORS ACCORDING TO THE IEEE 1812 TESTING GUIDE}

The recently approved IEEE 1812 testing guide contains general instructions for determining the performance characteristics of PM machines of different sizes and configurations. The guide includes steady-state tests for open-circuit, shortcircuit, load, and thermal performance, and transient tests for retardation or coastdown, and sudden short-circuit [11].

Results of "virtual tests", i.e. high fidelity FEA simulations under the specified IEEE 1812 conditions, are conducted for the spoke IPM motor with ferrites in Figs. 4 and 5. Virtual tests are performed at $6000 \mathrm{rpm}$ and several electric cycles were simulated in order to accommodate the numerical transients and reach steady-state. 


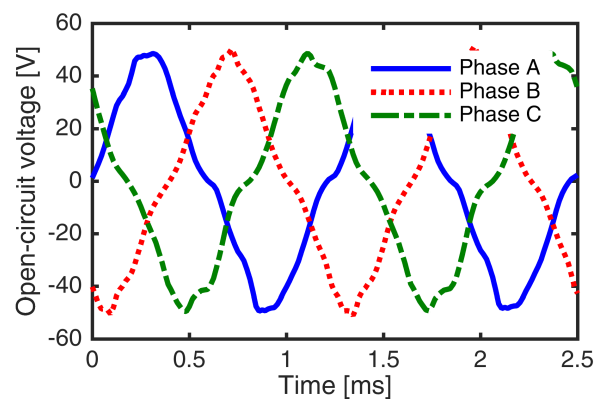

(a)

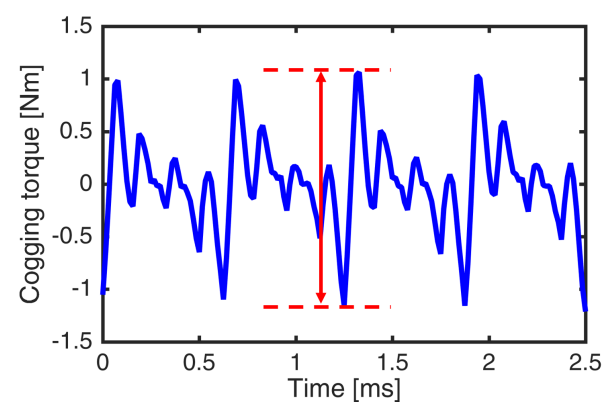

(b)

Figure 4. Open-circuit virtual test results for the spoke-type PM machine of Fig. 3 with ferrite magnets and specified reference dimensions. The FE calculated open-circuit losses in the M19 laminated core are $162 \mathrm{~W}$. (a) Open-circuit per phase voltages, (b) cogging torque which is very low, in line with expectations for this $18 / 16$ fractional slot/pole combination, below $2 \%$ of the rated value.

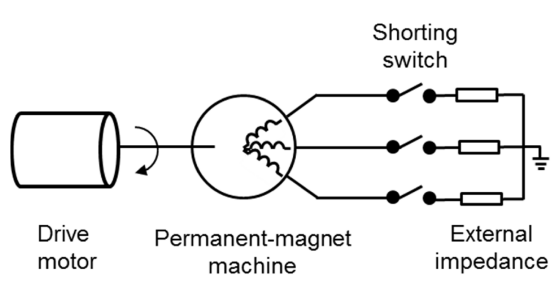

(a)

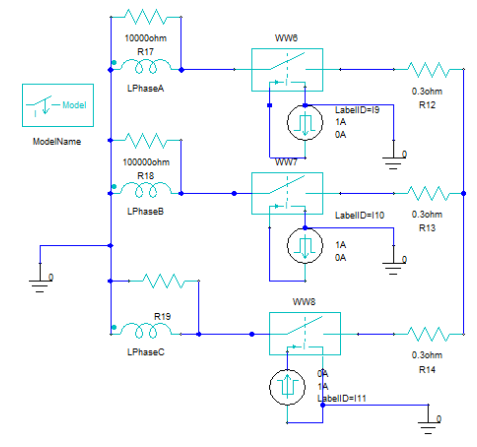

(b)

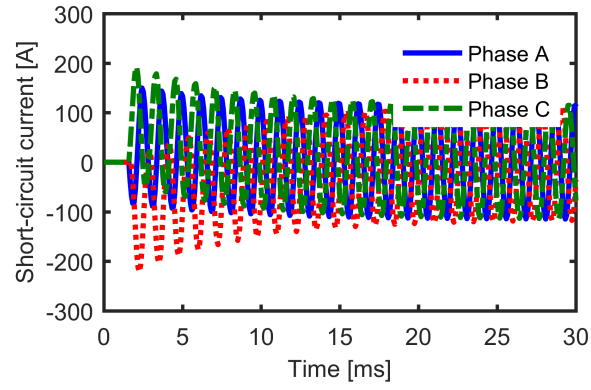

(c)

Figure 5. Short-circuit virtual test implementation and results. (a) Circuit diagram as per IEEE 1812 [11], (b) the equivalent external circuit implemented within the ANSYS Electronics Desktop environment for use with the Maxwell electromagnetic FEA software; the shorting switch is set to close at $1.5 \mathrm{~ms}$, (c) short-circuit current reaching steady-state.

According to the IEEE 1812 testing guide, the short-circuit test is conducted using a shorting switch and an optional external limiting impedance. The current, $I_{s c}$, is measured after the steady-state short-circuit condition is achieved and then the synchronous reactance $X_{s}$ can be calculated from:

$$
I_{s c}=\frac{V_{o c}}{\left|j X_{s}+R_{s}+j X_{e x}+R_{e x}\right|},
$$

where $R_{s}$ is the stator winding resistance that is negligible for the machine under study, and $X_{e x}$ and $R_{e x}$ are the external reactance and resistance, respectively. $X_{e x}$ is considered to be zero.

For IPM machines with saliency, such as the spoke motor considered in the exemplified case study, the air-gap is not uniform such that for the flux flowing through direct axis the air-gap is longer than the flux flowing through quadratic axis. This results in smaller $d$ axis inductance. Synchronous reactance, $X_{s}$, in (4) can be replaced by the $\mathrm{d}$ axis synchronous reactance $\left(L_{d}\right)$ for salient-rotor machines.

Equation (4) employs the voltage from open-circuit test and the current from short-circuit test. Therefore, this synchronous reactance calculation approach may be regarded as an open for debate approximation because the non-linear electromagnetic field conditions and the flux pattern are largely different between open-circuit and short-circuit operation and approximating their equality impacts the results. This is particularly important for the study at hand that deals with small deviations and tolerances.

\section{Design of Experiments (DOE) And Sensitivity ANALYSIS}

The primary intent of the DOE is to study the motor performance sensitivity on varying dimensions and material properties due to manufacturing tolerances to be able to determine the causes of out of specification performance.

Systematic DOE and sensitivity analysis are conducted for the purpose of this study. The first step in DOE is defining the factors and their levels. Figure 3 shows that 11 geometrical variables can capture the possible manufacturing deviations from the designed motor dimensions. In addition, magnet and laminated steel grades can also be affected by manufacturing tolerances. Hence, overall 13 factors are considered (Table I and II). In order to ensure that all possible non-linearities are taken into account, geometrical factors and remanence are evaluated in three levels. The lamination grade is specified to be M19, however it is considered that manufacturing nonidealities may degrade the properties to those of M43. Hence 


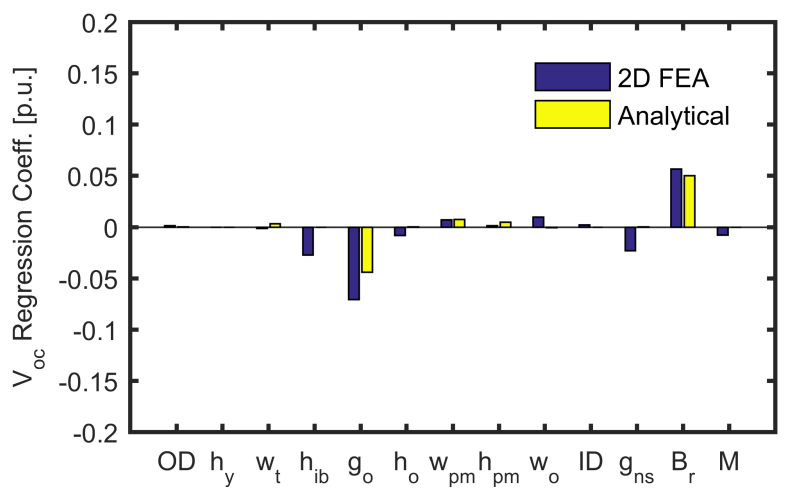

(a)

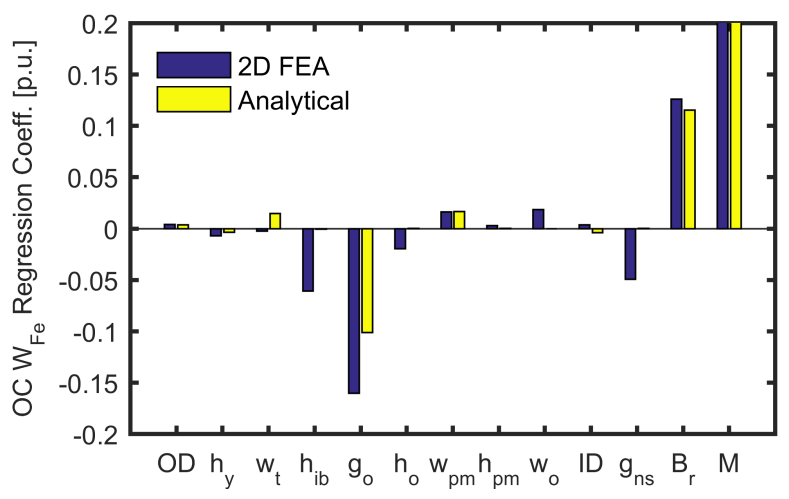

(b)

Figure 6. The regression coefficients in per unit calculated numerically and analytically for the motor with ceramic ferrite magnets; (a) open-circuit voltage, (b) core losses regression coefficients obtained from open-circuit tests. The bar corresponding to lamination material , $\mathrm{M}$, in (b) is out of scale and truncated and goes up to 0.23 for numerical and 0.3 for analytical.

2 levels for $M$ are considered. A full factorial design will result in thousands of designs such that conducting FEA for all of them is not affordable. Instead, a fractional factorial method, capable of collecting the necessary data for sensitivity analysis with a minimum amount of computational evaluations is employed, thus saving time and resources.

The response variables, i.e. output performance indices, chosen for the DOE study include from the open-circuit test, the voltage (back emf), cogging torque, and core losses and from the short-circuit test, the current and the synchronous daxis inductance. It should be noted that as per (4), unlike the measured short circuit current, the calculated d-axis inductance is correlated with the open-circuit voltage, which has implications in terms of the DOE mathematical formulation, i.e., the response variables must be independent. This is not the case for $L_{d}$, the evaluation of which is based on the recommended method for calculating $X_{s}$ (4). Therefore, it is preferred to directly use $I_{s c}$ as one of the performance parameters rather than $L_{d}$.

The sensitivity analysis is executed by fitting a regression

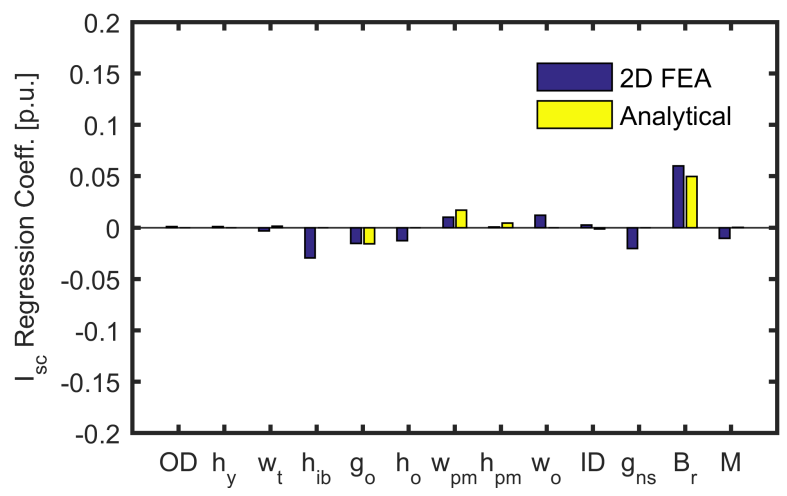

(a)

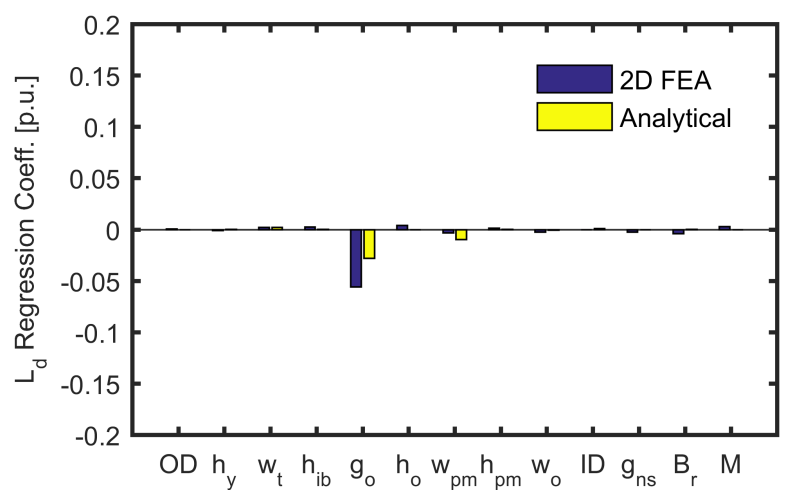

(b)

Figure 7. The regression coefficients in per unit resulted from numerical and analytical calculations for the motor with ceramic ferrite magnets; (a) d axis inductance, (b) short circuit current regression coefficients obtained from short-circuit test. Based on (4), $L_{d}$ is a function of another performance factor under study, i.e. $V_{o c}$. This will cause conflict between DOE responses that must be completely independent of each other. Therefore, only $I_{s c}$ is recommended to be utilized in determining the cause of inconsistency.

curve demonstrated by a polynomial function as

$$
\begin{aligned}
& Y= \beta_{0}+\sum_{i=1}^{d_{\nu}} \beta_{i} X_{C i}+\sum_{i=1}^{d_{\nu}} \beta_{i i} X_{C i}^{2}+ \\
& \sum_{i=1}^{d_{\nu}} \sum_{j=i+1}^{d_{\nu}} \beta_{i j} X_{C i} X_{C j}, \\
& X_{C i}=\frac{x_{i}-\left(x_{i, \max }+x_{i, \min }\right) / 2}{\left(x_{i, \max }-x_{i, \min }\right) / 2} ; i=1,2, \ldots, d_{\nu},
\end{aligned}
$$

where $Y$ is a response parameter; $\beta$, the regression coefficient; $d_{\nu}$, the number of factors (13 in this case), $x_{i}$, the $i^{t h}$ input factor; and $X_{C i}$, the normalized (coded) value of the $i^{t h}$ factor. Factors may be normalized as shown in (5). $X_{C i}=$ 0 represents the specified values of the factors with zero manufacturing error, and $\beta_{0}$ is a representation of response parameter in this reference situation. $\beta_{i i}$ and $\beta_{i j}$ illustrate second order effects caused by non-linearity and interaction between the factors.

Based on the findings from DOE, it is concluded that the interaction and higher order terms are negligible for this 


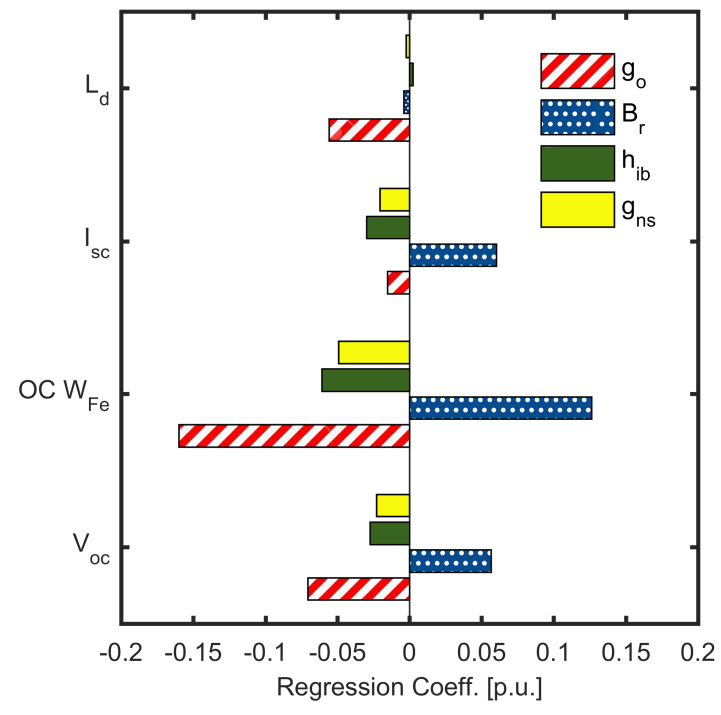

(a)

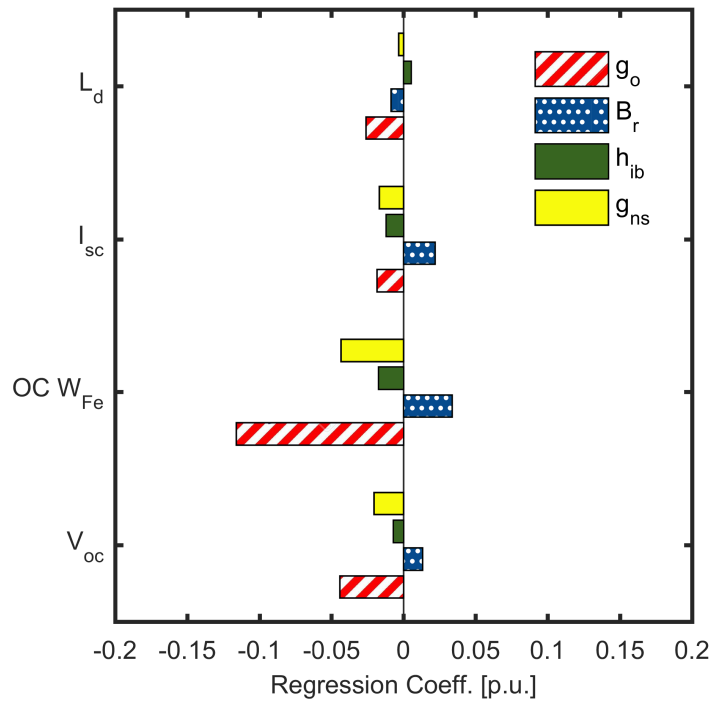

(b)

Figure 8. The regression coefficients for only the most significant factors in determining the influence on output parameters. The values are resultant from numerical analysis for the spoke-type motor with a) ceramic ferrite magnets, and b) rare earth SmCo magnets. Lamination material, M, has a significant effect only on core losses hence it has been omitted from the figure for the sake of simplicity.

study. Accordingly, a first order regression model is fit and the regression coefficients are estimated using least-squares method. The per unit values of regression coefficients are defined as $\frac{\beta_{i}}{\beta_{0}}$. As an instance, $V_{o c}$, obtained from numerical analysis of the model with ferrite magnets can be estimated using the polynomial function,

$$
\begin{aligned}
Y_{\left(V_{o c}\right)} & =54.06+0.08 X_{C 1}-0.02 X_{C 2}-0.08 X_{C 3}- \\
& 1.47 X_{C 4}-3.83 X_{C 5}-0.45 X_{C 6}+0.38 X_{C 7}+ \\
& 0.08 X_{C 8}+0.52 X_{C 9}+0.10 X_{C 10}-1.24 X_{C 11}+ \\
& 3.06 X_{C 12}-0.42 X_{C 13}
\end{aligned}
$$

and the polynominal function estimating $V_{o c}$ for the motor with SmCo magnets is obtained as

$$
\begin{aligned}
Y_{\left(V_{o c}\right)} & =146.83+0.16 X_{C 1}+0.02 X_{C 2}+0.32 X_{C 3}- \\
& 1.06 X_{C 4}-6.5 X_{C 5}-1.7 X_{C 6}+0.43 X_{C 7}+ \\
& 0.15 X_{C 8}+0.46 X_{C 9}+0.19 X_{C 10}-3 X_{C 11}+ \\
& 1.94 X_{C 12}+1.31 X_{C 13} .
\end{aligned}
$$

Regression coefficients values represented in Figs. 6 and 7 illustrate the effect of tolereances of the input variables on performance parameters obtained from open-circuit and shortcircuit tests, respectively. Cogging torque is not considered since, for the slot-pole combination of the machine under study, its value is negligible. Negative regression coefficients indicate that the response reduces upon increase in the corresponding factor. The larger the magnitude of the regression coefficients, the more influential the factor.

Some important takeaways from Figs. 6 and 7 are:

1) based on numerical analysis, the output response parameters under study for this machine are more significantly sensitive to tolerances in air-gap, $g_{o}$, remanence, $B_{r}$, bridge height in the inner diameter of the rotor, $h_{i b}$, and nuisance gap between PMs and core walls, $g_{n s}$. The impact of the rest of the factors is negligible.

2) the effects of $h_{i b}$ and $g_{n s}$ are not fully captured in the analytical studies. The changes in these two factors affecting saturation and leakage flux, have second order effects on response parameters, which can only be poorly estimated analytically.

3) lamination material has an observable effect only on the core losses.

4) open-circuit core loss is the most sensitive response parameter to the tolerances. This may be understood by considering the relationship between input variables and output parameters. While EMF is proportional to the flux density, core loss is proportional to its square (2), thus explaining its higher sensitivity to all variables that may affect flux density.

A similar study for the second machine design, obtained on replacing ferrite magnets with rare earth SmCo magnets, is also conducted. A comparison between regression coefficients of only significant factors for the motor with ferrite and rare earth magnets is plotted in Fig. 8. The performance parameters of the motor with stronger magnet grade (rare earth magnets), Fig. 8b, represents lower sensitivity to changes in input variables, especially $h_{i b}$ and $g_{n s}$. This motor operates under an exceptionally high magnetic loading such that the rotor core is saturated at the inner diameter. Therefore, for instance, larger bridge height does not result in more leakage flux and hence output performance is not considerably affected by changes in it. 


\section{Discussion AND EXAMPLE SCENARIOS}

Sensitivity analysis for responses from open-circuit $-V_{o c}$ and core losses- and short-circuit tests-preferably, $I_{s c}$ may be used to indicate possible sources of deviations from the nominal values. Each of these three responses might represent a value more than, less than, or equal to the rated values which means 27 different scenarios can occur. Discussing every one of them is not feasible in a limited space, however some examples are studied to introduce the approach.

For simplification, it is assumed that only the factors with regression coefficients above 0.02 p.u. can significantly affect a response. This means, refering to Figs. 8a, $I_{s c}$ of the motor with ferrite is not affected by $g_{o}$ or $g_{n s} ; V_{o c}$ of the motor with SmCo is only affected by $g_{o}$; loss of the same motor is not affected by $h_{i b}$; and $I_{s c}$ is only affected by $B_{r}$ (Fig. 8b).

The first example scenario considers the case when all parameters are consistent with their rated value and only opencircuit core losses deviate. This could indicate undesirable substitution in the lamination grade which can be further accentuated through supplementary testing at higher speed(s).

Assuming a scenario with unexpected results for core loss measurement, for the motor with ferrite magnets, if $V_{o c}$ or $I_{s c}$ are also inconsistent in the same direction i.e., loss, $V_{o c}$, and $I_{s c}$ all lower or higher than rated value - then any of the factors or a combination of several of them could be out of specifications. However, if the direction of inconsistency is not the same-e.g. lower loss, higher $V_{o c}-$ most probably more than one variable is out of specifications.

For the spoke motor with high magnetic loading, ignoring all inputs with regression coefficients below 0.02 p.u., $V_{o c}$ is only affected by $g_{o}$ and $I_{s c}$ is only influenced by $B_{r}$. Thus, in a situation that both parameters deviate from rated values, at least two variables, $g_{o}$ and $B_{r}$ are out of specification. If only $V_{o c}$ or only $I_{s c}$ deviate, the out of specification variable may be identified. Deviations in only $V_{o c}$ indicate that the air-gap is out of specifications, and deviations in only $I_{s c}$ may imply that remanence is out of specifications.

In case of SPM machines factors such as $h_{i b}$ and $g_{n s}$ are irrelevant. Therefore, tracing the variable influenced by manufacturing tolerance may be less complicated.

The examined instance scenarios specify that identification of manufacturing tolerances and out of specification variables is strongly dependent on the ratings and configuration of the machine as well as its operating point. A comprehensive case-by-case sensitivity analysis accompanied by engineering judgment may help in narrowing down the possible nonidealities caused by manufacturing/prototyping tolerances.

\section{CONCLUSION}

The paper proposes a new systematic method that employs a combination of only the open-circuit and short-circuit tests performed according to the recently approved IEEE standard 1812 testing guide for PM synchronous machines and DOE techniques in order to identify possible out of specification variations of the main design variables and material characteristics. The approach has the great advantage of using the most straightforward and reproducible tests, having minimum instrumentation and test bed requirements.

The method was demonstrated on a case study using virtual tests with high fidelity simulation models that have been previously validated. The results indicate that in case all dimensional variables and magnet remanence are manufactured precisely, the variations in lamination grade may be identified by means of a variable speed open-circuit test. Through the combined and comparative analysis of open-circuit and short-circuit test variations, the influence of the dimensional tolerances, especially of the air-gap as well as remanence can be further identified.

Determining the out of specification variables or narrowing them down to the most probable options needs careful consideration of the machine topology as well as an extensive sensitivity analysis. Generalization of the effects of manufacturing tolerances of one machine based on experiments conducted on another, may not result in valid outcomes, as illustrated in this paper for two 16 slot 18 pole spoke PM topologies, similar in all respects, excepting the magnet grade.

\section{REFERENCES}

[1] Y.-K. Kim, J.-P. Hong, and J. Hur, "Torque characteristic analysis considering the manufacturing tolerance for electric machine by stochastic response surface method," IEEE Transactions on Industry Applications, vol. 39, no. 3, pp. 713-719, May 2003.

[2] I. Coenen, M. V. der Giet, and K. Hameyer, "Manufacturing tolerances: Estimation and prediction of cogging torque influenced by magnetization faults," IEEE Transactions on Magnetics, vol. 48, no. 5, pp. 1932-1936, May 2012.

[3] A. J. P. Ortega, S. Paul, R. Islam, and L. Xu, "Analytical model for predicting effects of manufacturing variations on cogging torque in surface-mounted permanent magnet motors," IEEE Transactions on Industry Applications, vol. 52, no. 4, pp. 3050-3061, July 2016.

[4] X. Ge and Z. Q. Zhu, "Sensitivity of manufacturing tolerances on cogging torque in interior permanent magnet machines with different slot/pole number," in 2016 IEEE Energy Conversion Congress and Exposition (ECCE), Sept 2016, pp. 1-8.

[5] M. Balluff, H. Naumoski, and K. Hameyer, "Sensitivity analysis on tolerance induced torque fluctuation of a synchronous machine," in 2016 6th International Electric Drives Production Conference (EDPC), Nov 2016, pp. 128-134.

[6] L. Wu, R. Qu, B. Song, H. Bi, O. Jing, G. Yang, and C. Du, "Analysis of cogging torque in surface permanent magnet machine with manufacturing tolerances," in IECON 2015 - 41st Annual Conference of the IEEE Industrial Electronics Society, Nov 2015, pp. 004 732-004 737.

[7] V. Simn-Sempere, M. Burgos-Payn, and J. R. Cerquides-Bueno, "Influence of manufacturing tolerances on the electromotive force in permanent-magnet motors," IEEE Transactions on Magnetics, vol. 49, no. 11, pp. 5522-5532, Nov 2013.

[8] P. Eklund and S. Eriksson, "Air gap magnetic flux density variations due to manufacturing tolerances in a permanent magnet synchronous generator," in 2016 XXII International Conference on Electrical Machines (ICEM), Sept 2016, pp. 93-99.

[9] F. Gillon and P. Brochet, "Screening and response surface method applied to the numerical optimization of electromagnetic devices," IEEE Transactions on Magnetics, vol. 36, no. 4, pp. 1163-1167, Jul 2000.

[10] A. Fatemi, D. M. Ionel, M. Popescu, and N. A. O. Demerdash, "Design optimization of spoke-type pm motors for formula e racing cars," in 2016 IEEE Energy Conversion Congress and Exposition (ECCE), 2016.

[11] "IEEE trial-use guide for testing permanent magnet machines," IEEE Std 1812-2014, pp. 1-56, Feb 2015. 